\title{
Environmental Safety Analysis Tests on the Light Weight Radioisotope Heater Unit (LWRHU)
}

\author{
R. E. Tate \\ C. C. Land
}

\begin{abstract}
DISCLAIMER
This report was prepared as an accuunt of work sponsored by an agency of the United States Government. Neither the Urited States Government nor any agency thereof, acr any of their employees, makes any warranty, express or implied, or assumes any legal liability or respons:bility for the accuracy, completeness, or usefulness of any information, apparatus, product, or process disclosed, or represents that its use would not infringe privately owned rights. Reference herein to any specific commercial product, process, or service by trade name, trademark, manufacturer, or otherwise does not necessarily constitute or imply its endorsement, recommendation, or favoring by the United States Government or any agency thereof. The views and opinions of authors expressed herein do not necessarily state or reflect those of the United Staies Government or any agency thereof.
\end{abstract}
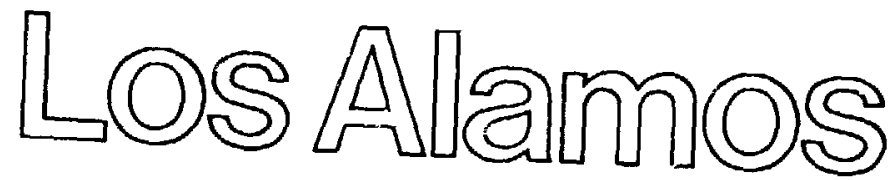


\title{
ENVIRONMENTAL SAFETY ANALYSIS TESTS ON THE LIGHT WEIGHT RADIOISOTOPE HEATER UNIT (LWRHU)
}

\author{
by
}

\author{
R. E. Tate and C. C. Land
}

\begin{abstract}
A series of safety tests has been performed on the Light Weight Radioisotope Heater Unit (LWRHU), a ${ }^{238} \mathrm{PuO}_{2}$-fueled device designed to provide thermal energy at selected locations in a spacecraft. The tests simulate the thermal and mechanical environments postulated for spacecraft accidents on the launch pad and on reentry abort. The tests demonstrate almost complete containment of the fuel, or fuel simulant (depleted $\mathrm{UO}_{2}$ ), in (1) an overpressure environment of 12.76 MPa (1850 psi), (2) on impact by an $18-\mathrm{g}$ aluminum fuel-tank fragment at velocities greater than $750 \mathrm{~m} / \mathrm{s}(2460 \mathrm{ft} / \mathrm{s})$ but less than $900 \mathrm{~m} / \mathrm{s}(2950 \mathrm{ft} / \mathrm{s})$, (3) during a 10.5 -min burn of a $0.9 \times 0.9 \times$

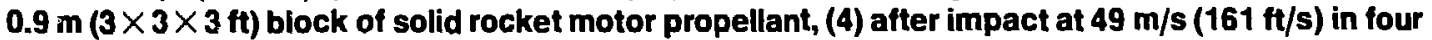
different orientations on a hard surface, and (5) during immersion in seawater for 1.75 years at both sea level pressure and at a pressure equivalent to $6000 \mathrm{~m}$ (19 $700 \mathrm{ft}$ ) of ocean depth.
\end{abstract}

\section{INTRODUCTION}

The Light Weight Radioisotope Heater Unit (LWRHU), a new radioisotope heater unit for use in space missions, is a ${ }^{238} \mathrm{PuO}_{2}$-fueled unit designed to provide thermal energy in selected locations on a spacecraft. The primary objective of the series of safety tests described in this report is to determine the response of the LWRHU when it is exposed to thermal and mechanical environments similar to those of accidents that have been postulated for space missions. Prime importance has been placed on determining the fuel containment capability of the unit during the tests.

The Los Alamos National Laboratory was the lead laboratory in the LWRHU design effort, which began in 1978. The design objective was a $1-W(t)$ unit with low mass, minimum dimensions, and an improved margin of safety. The original schedule required design, development testing, production, and delivery in 14 months. However, postponement of the Galileo mission launch for other reasons permitted more iterations in the design process, enabling us to develop a design with an enhanced safety margin and allowing for additional environmental testing of the unit's capabilities. The unit developed is illustrated in Fig. 1. Its features and design development are fully described in Ref. 1.
The postulated accidents to which the LWRHU might be exposed can be divided into two groups: launch pad events that expose the unit to explosion overpressure, high-velocity fragments, and burning solid rocket motor propellant; and reentry events that expose the unit to reentry heating, aeroshell ablation, hard-earth impact, and seawater immersion. A test plan was developed in 1981 to evaulate experimentally the fuel containment capability of the LWRHU in most of these environments. ${ }^{2}$

For the experiments. another division was necessary. In the overpressure, fragment, and propellant-fire tests, units with simulant (depleted $\mathrm{UO}_{2}$ ) fuel pellets were used because release of $\mathrm{PuO}_{2}$ at these test facilities could not be tolerated. Speciai facilities designed for ${ }^{238} \mathrm{PuO}_{2}$ had been developed for impact testing and for seawater exposure. Productiontype units were tested in these environments. Reentry heating and ablation are difficult to simulate in the laboratory. However, during the LWRHU design phase, computer simulations were able to predict the heat of reentry. ${ }^{1}$ Using these predictions, we simulated reentry heating by subjecting the bare fueled clads to a short-duration thermal pulse. After this thermal conditioning, the capsules were reassembled with the 


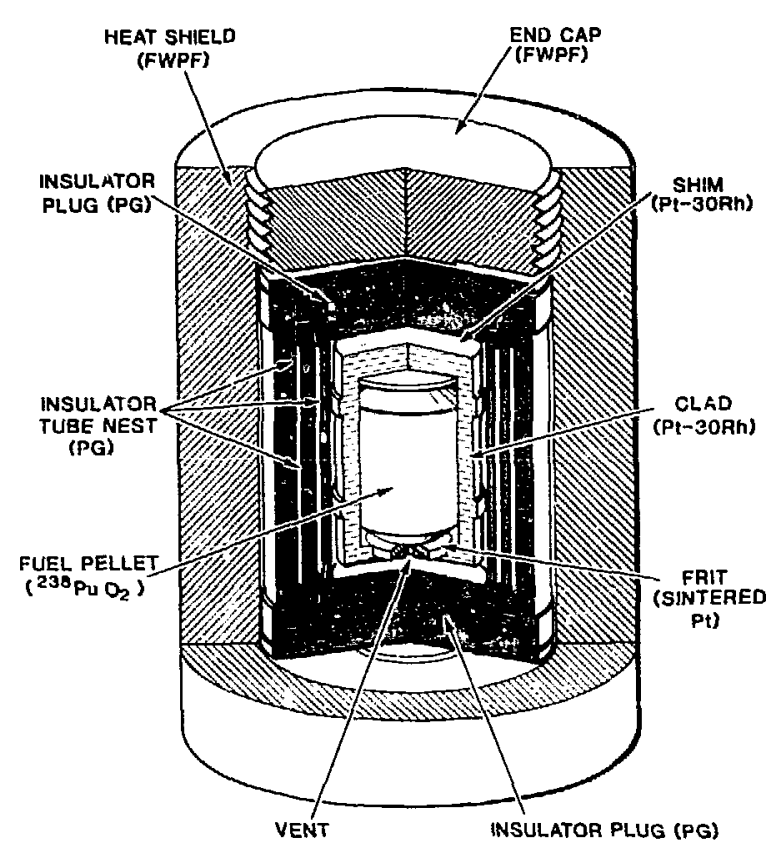

Fig. 1. Light Weight Radiorsotope Heater Unit.

graphite components, and the LWRHUs I ere impacted.

\section{TEST HARDWARE}

Nineteen LWRHU units were used in the safety analysis test program. Eight units were fueled with production-grade ${ }^{238} \mathrm{PuO}_{2}$ pellets and eleven units were loaded with cold-pressed and sintered depleted $\mathrm{UO}_{2}$ that had been ground to the appropriate dimensions. The fueled units were loaded and welded in the production glove box line. The simulant units were prepared early in the design and development phase and were loaded and weided in the open laboratory under somewhat less stringent welding parameters.

The components of the LWRHU device shown in Fig. 1 are (1) a cylindrical ceramic fuel pellet nominally $6.25 \mathrm{~mm}$ in diameter and $9.35 \mathrm{~mm}$ high with chamfered ends; (2) a Pt-30 Rh containment capsule $8.65 \mathrm{~mm}$ in diameter and $12.6 \mathrm{~mm}$ high, which contains a frit vent system to permit release of the helium generated by radioactive decay; (3) a pyrolytic graphite insulator system built from three concentric tubes with standoif rings and stepped end caps; and (4) a FWPF* aeroshell and closure plug that provides protection in an atmospheric reentry event. Each of these components has a serial number that is indexed to the manufacturing history and characteristics of the component. For convenience, the serial number of the aeroshell, of the form LRF XXX, will be used to identify the unit assembly tested. The unit is a right circular cylinder 26 $\mathrm{mm}$ in diameter and $32 \mathrm{~mm}$ high, it weighs a nominal 40 $\mathrm{g}$, and it produces $1.1 \mathrm{~W}(\mathrm{t})$ at the beginning of its life.

For the overpressure and fragment (bullet) tests, the units were mounted on a Galileo Orbiter magnetometer plate, a 6061-T651 aluminum-alloy ring 16.76$\mathrm{mm}(6.600$-in.) o.d., 10.16-mm (4.000-in.) i.d., and 1.27 $\mathrm{mm}(0.500$ in.) thick. Mounting cups of the same aluminum alloy with a nominal $0.13-\mathrm{mm}(0.050$-in.) wall thickness screw into the magnetometer plate at three equidistant locations and these cups, with Belleville washer inserts, held the test units firmly in contact with the magnetometer piate at the beginning of overpressure and fragment tests.

\section{LAUNCH PAD ENVIRONMENTS}

Simulant-fueled LWRHUs were used in the launchpad-accident environment tests because these testbed areas cannot tolerate the possibility of potential ${ }^{238} \mathrm{Pu}$ fuel dispersal. The overpressure/shock 'ube, bullet/fragment, and rocket propellant burn tests were conducted in open-air facilities using techniques that preclucied assurance of total fuel containment.

\section{A. Overpressure}

To evaluate the response of the LWRHU assemblies to blast effects, two tests were conducted at Sandia National Laboratories' Coyote Test Range (Albuquerque, New Mexico). In the tests, we used a shock

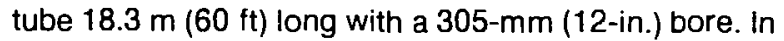
the first test, unit LRF 007 was installed on a magnetometer plate, which was in turn mounted on a foamed plastic pedestal in the muzzle of the shock tube $17.8 \mathrm{~m}$ $(58.4 \mathrm{ft}$ ) from the breech (see Fig. 2). The catch box shown in Fig. 3 was built of massive concrete blocks. It was filled with sawdust, and a sheet of insulation board at the impact face retained the sawdust in the box. The distance between the tube muzzle and the impact face of the catch box was $1.8 \mathrm{~m}(6 \mathrm{ft})$. The armored $\mathrm{x}$-ray film cassettes placed parallel to the capsule trajectory are shown in Fig. 4 . The blast wave was generated by a 73.5-kg (162-lb) composition $\mathrm{C}-4$ explosive charge

-Fineweave-Pierced Fabric 3-D carbon/carbon composite, a product of AVCO Systems Division, 201 Lowell St., Wilmington. MA 01887. 


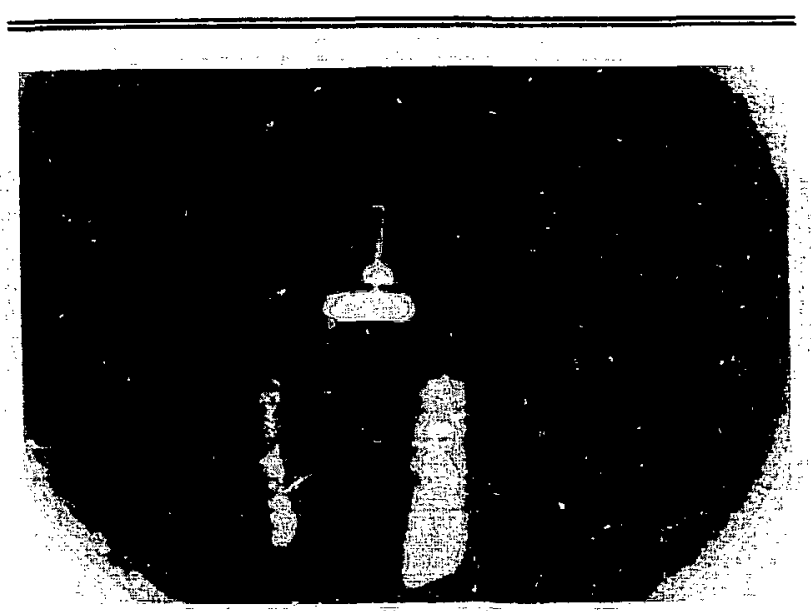

Fig. 2. LWRHU assembly on foamed plastic pedestal in shock tube for first overpressure test.

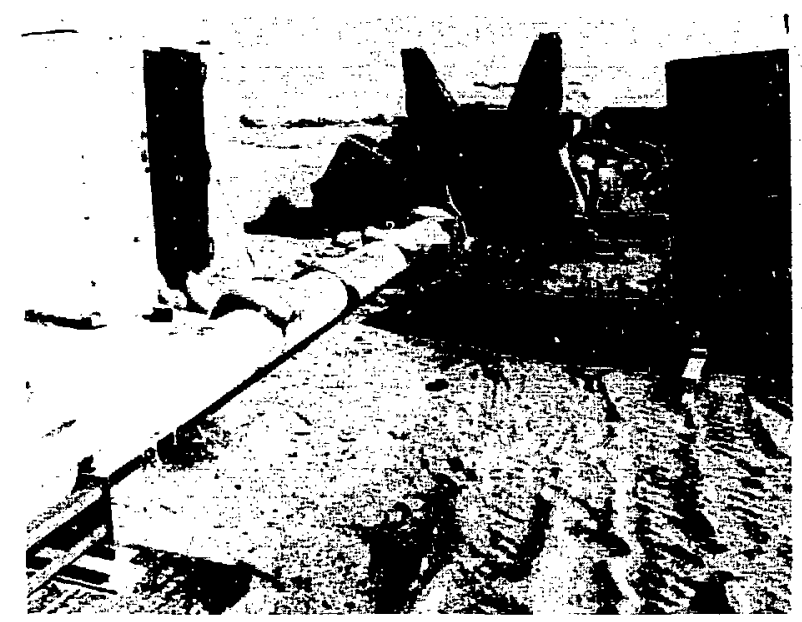

Fig. 3. Shock-tube muzzle end and catch box for first overpressure test.

placed in a steel can $25.4 \mathrm{~mm}$ (1 in.) thick and open toward the shock-tube breech. The breech end of the shock tube is shown in Fig. 5. Readings from three pressure gauges indicate that the target unit was subjected to a static overpressure of $12.76 \pm 0.69 \mathrm{MPa}$ $(1850 \pm 100 \mathrm{psi})$. Integration of the pressure-time traces indicates that the static impulse was $38.6 \pm 3.4$ $\mathrm{kPa} \cdot \mathrm{s}(5.6 \pm 0.5 \mathrm{psi} \cdot \mathrm{s})$ at the target location.

Upon arrival of the shock wave, the graphite components and the aluminurn-alloy cup attaching the target

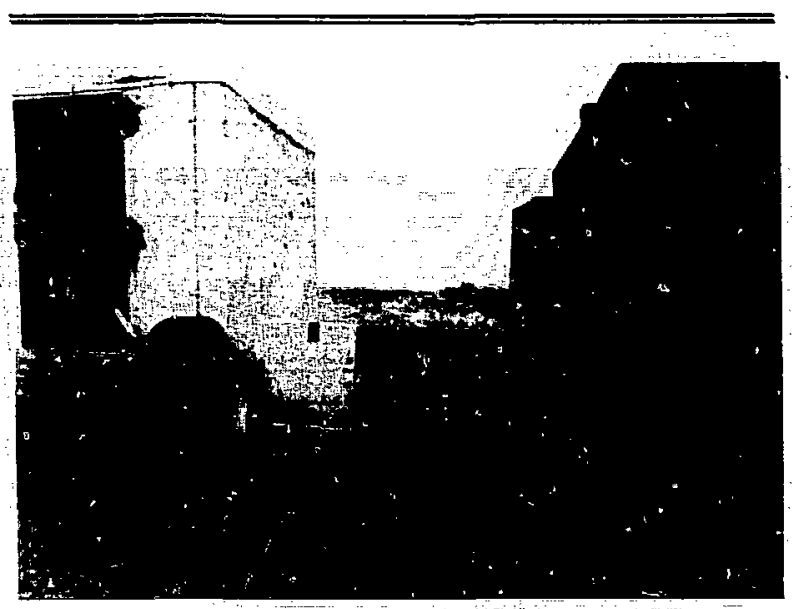

Fig. 4. X-ray film cassettes for first overpressure test

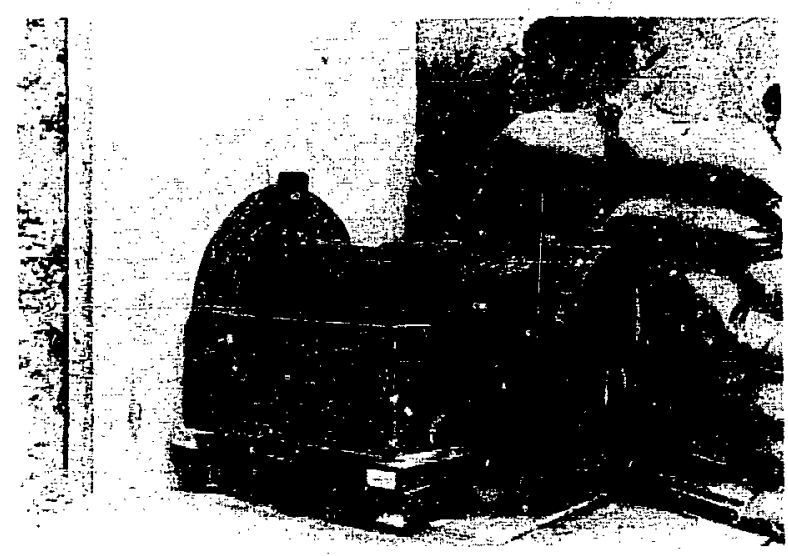

Fig. 5. C-4 explosive charge at breech of shock tube.

unit to the magnetometer plate were stripped from the simulant-fueled capsule as it was propelled toward the catch box. A flash $x$-ray picture of the capsule in flight showed an undistorted profile image of the capsule, indicating probable capsule integrity at this point. From the position of the capsule image on the $x$-ray film and from knowledge of the detonation and $x$-ray timing, we can estimate that the capsule was moving toward the catch box at : velocity of $1310 \mathrm{~m} / \mathrm{s}(4300 \mathrm{ft} / \mathrm{s})$. Incidentally, the protected film cassettes weighing $27 \mathrm{~kg}(60 \mathrm{lb})$ were recovered as far as $91 \mathrm{~m}$ (100 yds) from their initial position, indicating the violent conditions near the shock-tube muzzle. 
After the blast, the catch box was a jumbled array of massive blocks with little resemblance to its original form. Figure 6 shows two posttest photographs of the catch-box area. The capsule was not recovered despite several thorough searches through the sawdust with a metal detector. It may have escaped through an opening created in the concrete blocks when they were in motion. High-speed camera coverage of the event indicates that there was leakage from the top and rear of the catch box.

The second overpressure test was conducted in an almost identical manner to the first test. However, two minor changes were made in the test setup. First, the three units LRF 004,006, and 016, attached to a magnetometer plate, were suspended from a foamed plastic slab positioned in the muzzle of the shock tube

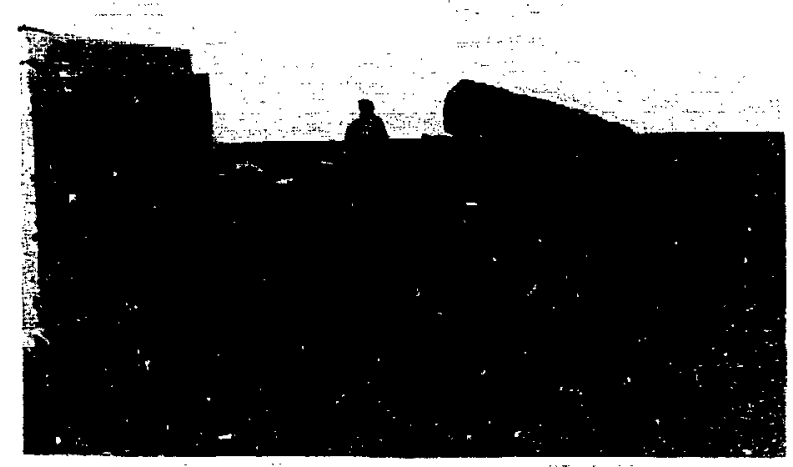

(a)

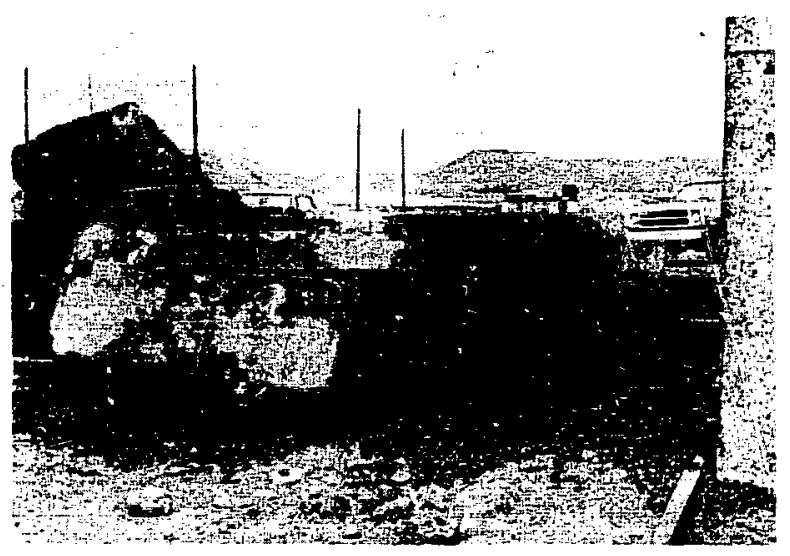

(b)

Fig. 6. Two views of catch box after first overpressure test. with the target units pointing down, as shown in Fig. 7 . Second, the distance from the tube muzzle to the catch

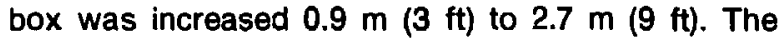
explosive driver was identical to that used in the first test. For this reason, pressure measurements were not made during this test. Because of faulty timing for the flash $x$-ray equipment, no images of the capsules in flight were obtained.

After the second test, the catch box was intact and two capsules, stripped of their graphite components, were recovered. The capsule from unit LRF 016 was not recovered. Figures $8 \mathrm{a}, 8 \mathrm{~b}$, and 9 are posttest photographs of units LRF 004 and 006, respectively. Field examination of the two recovered capsules indicated that both capsules were deformed, 004 more severely, but not breached. Metallographic examination, however, showed that 004 had been breached in the area of the closure weld, as is shown in the longitudinal section (Fig. 8b). This section also shows incompleid weld penetration in this unit. This capsule apparently failed because of poor welding; if the vertical joint had been fused, the failure probably would not have occurred. The lack of weld penetration shown in this simulant-fueled unit, produced early in the fabrication development, has not been observed in flightqualified ${ }^{238} \mathrm{PuO}_{2}$-fueled capsules.

Tine results of these two tests show that the fuel containment capability of the LWRitU fuel capsule is not impaired by the overpressure environment at the

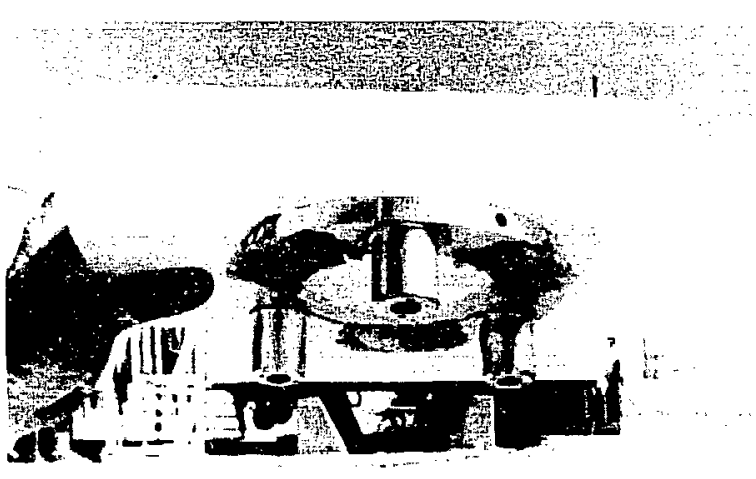

Fig. 7. LWRHU assembly on foamed plastic support for the second overpressure test. 


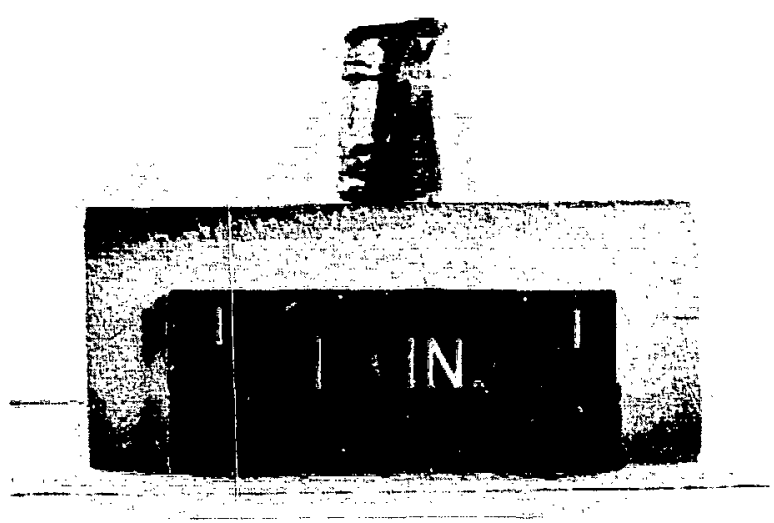

(a)

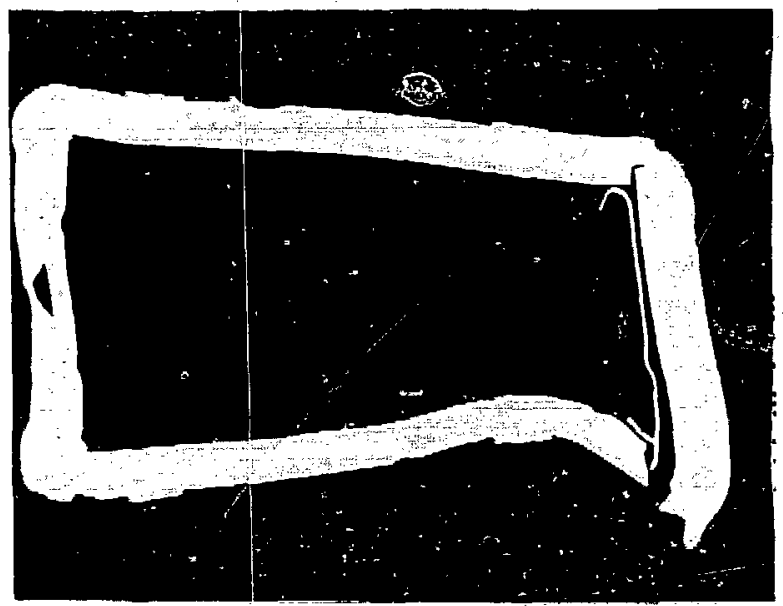

(b)

Fig. 8. Profile view of unit LRF 004 (a) after overpressure test. (b) Longitudinal section of unit ( $8 \mathrm{X})$.

level tested. However, such an environment does remove the graphite protection so that any subsequent environmental insults will be faced by the bare fuel capsule.

\section{B. Fragment}

In the test, .50-caliber bullets, machined from the special aluminum alloy (2219-T87) used in the space shuttle external tank, were fired at simulant-fueled LWRHU assemblies to evaluate the resistance of the heat source to frag.nents ger,erated in a postulated

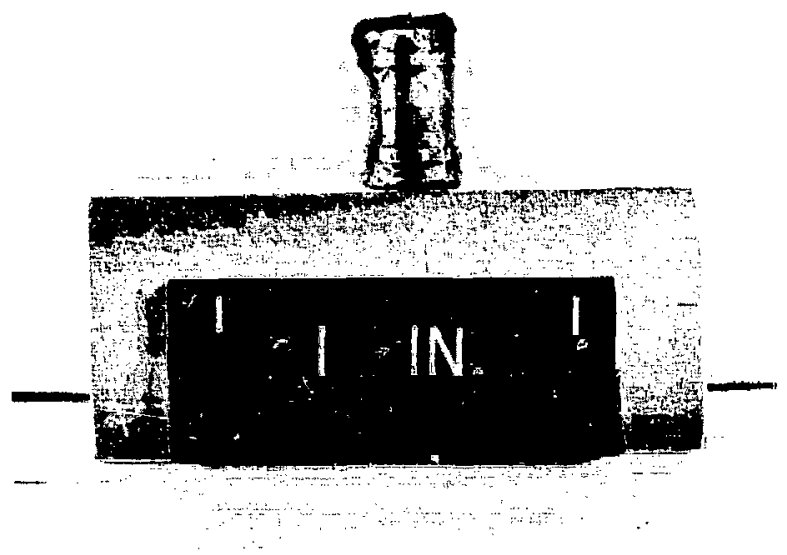

(a)

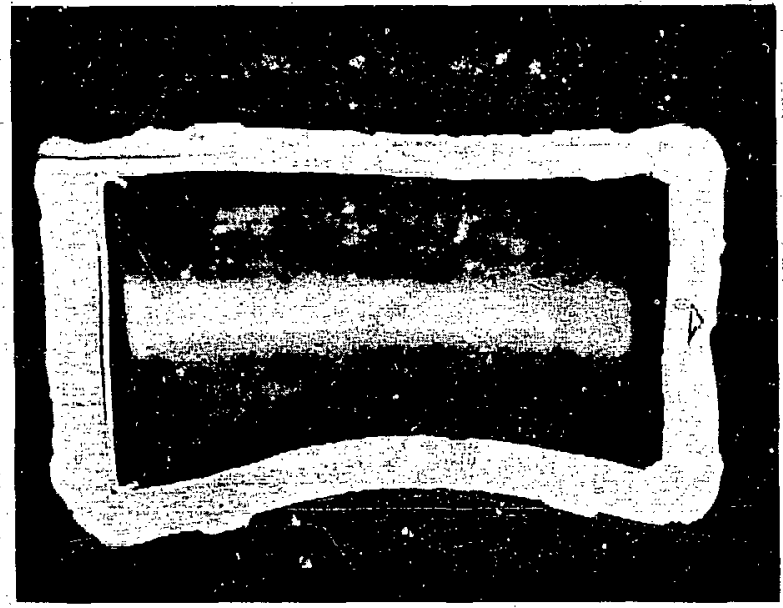

(b)

Fig. 9. Profile view of unit LRF 006 (a) after overpressure test. (b) Longtudinal section of unit (8X).

launch-pad detonation event. The length of the bullet/fragment was adjusted by machining so that it weighed $18 \mathrm{~g}$. Figure 10 gives the dimensions of the bullet, and the bullet/fragment is pictured in Fig. 11. By adjusting the powder loading in the .50-caliber cartridge case and by filling the remaining case volume with bran, we fired bullets at various velocities ranging - from about 305 to $914 \mathrm{~m} / \mathrm{s}$ (1000 to $3000 \mathrm{ft} / \mathrm{s})$. Simulant-fueled heat source units were installed singly on a magnetometer ring (Fig. 12), which was then placed in the impact area at the Q-Site firing facility at Los Alamos. The gun used to fire the projectiles is a thickwalled .50-caiiber barrel mounted on a heavy pedestal, 


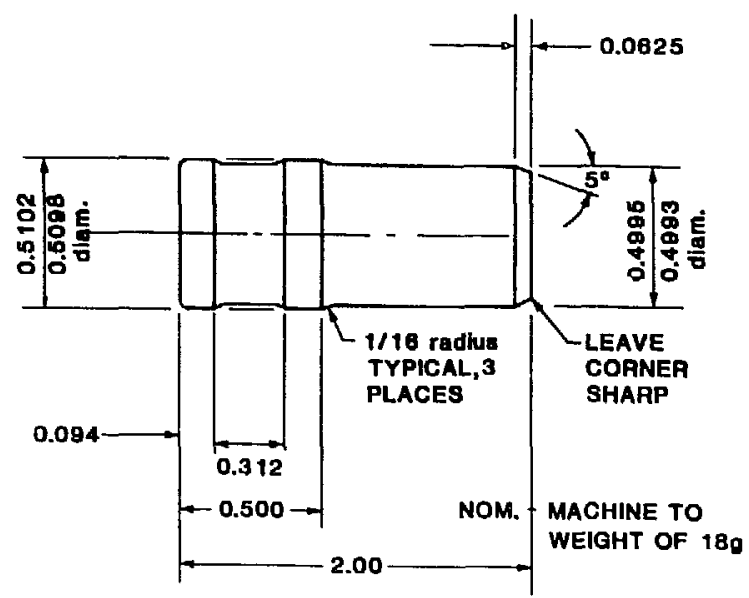

ALL DIMENSIONS IN INCHES

Fig. 10. Bullet (fragment) dimensions.

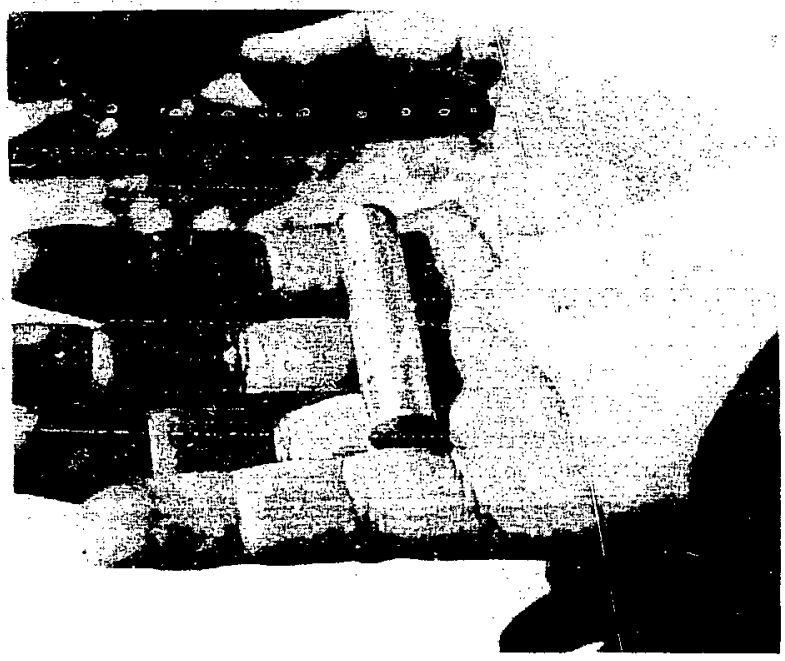

Fig. 11. Photograph of fragment (.50-caliber bullet).

as shown in Fig. 13. This gun is aimed with a telescopic bore sight, and the aim line is adjusted with vernier handwheels. The Q-Site facility is equipped with velocity traps to measure the projectile velocity and with flash $x$-ray equipment to record the position of the bullet just before it impacts the target.

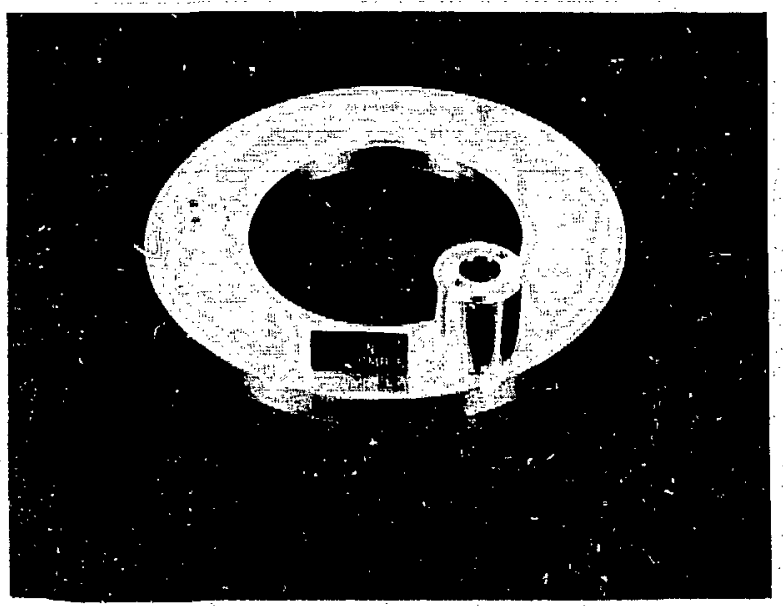

Fig. 12. Target for LWRHU fragment test; LWRHU mounted on magnetometer ring.

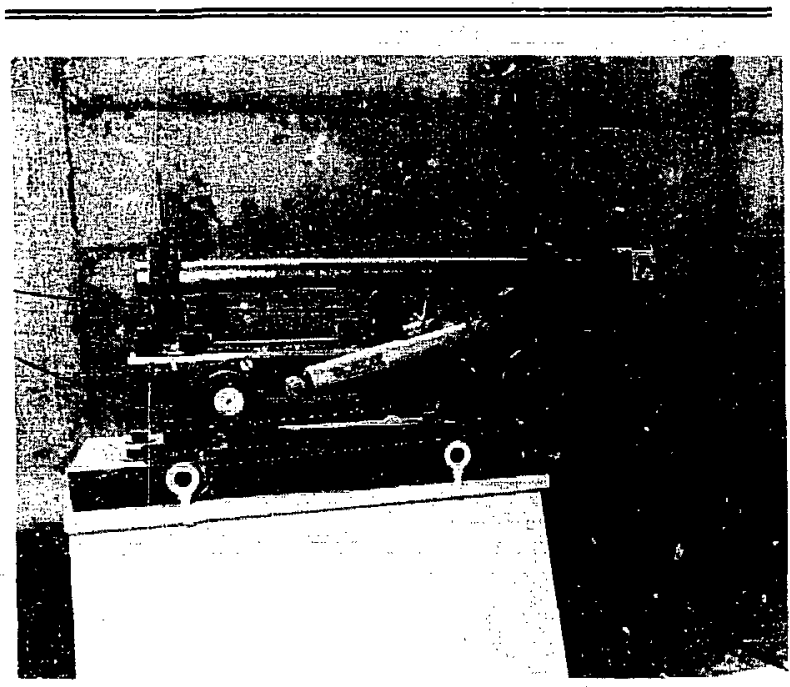

Fig. 13. The .50-caliber gun used for fragment test.

A flash $x$-rav image of the fragment about to impact a LWRHU assembly is shown in Fig. 14. The arrangement of the target area for the fragment test is shown in Fig. 15, and a posttest closeup view is shown in Fig. 16. Seven tests ware conducted; the conditions and results are summarized in Table $\mathrm{I}$. At velocities from 289 to $757 \mathrm{~m} / \mathrm{s}$ (948 to $2483 \mathrm{ft} / \mathrm{s}$ ), capsules were deformed but not breached. In the two tests at the highest velocities, 908 and $940 \mathrm{~m} / \mathrm{s}$ (2979 and 3083 $\mathrm{ft} / \mathrm{s})$, no physical lemnants of the target capsules were 


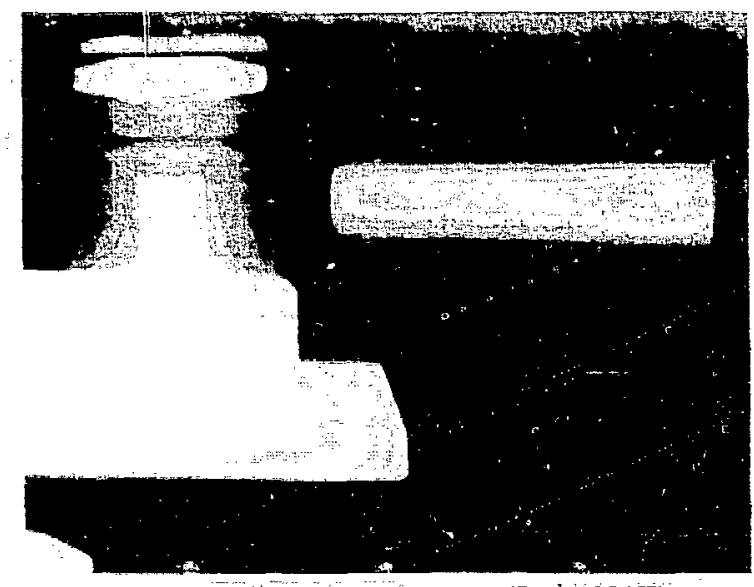

Fig. 14. Flash $x$-ray of fragment about to impact LWRHU assembly.

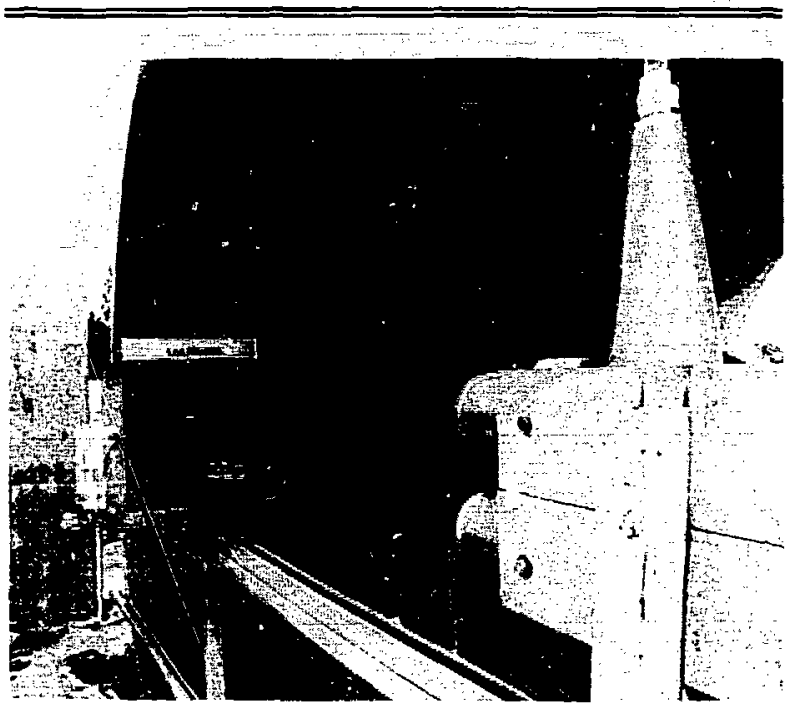

Fig. 15. Target area for LWRHU fragment test; $x$-ray generator on the right, LWRHU target, and film cassette.

found, but a significant amount of uranium was detected in the graphite debris collected from the catch area. Uranium in the posttest debris is interpreted as failure of the containment capability of the capsule. In the test of unit LRF 008, the bullet struck the holder offcenter and destroyed the graphite, bui did not strike the capsule. In the test of unit LRF 018, no fragments

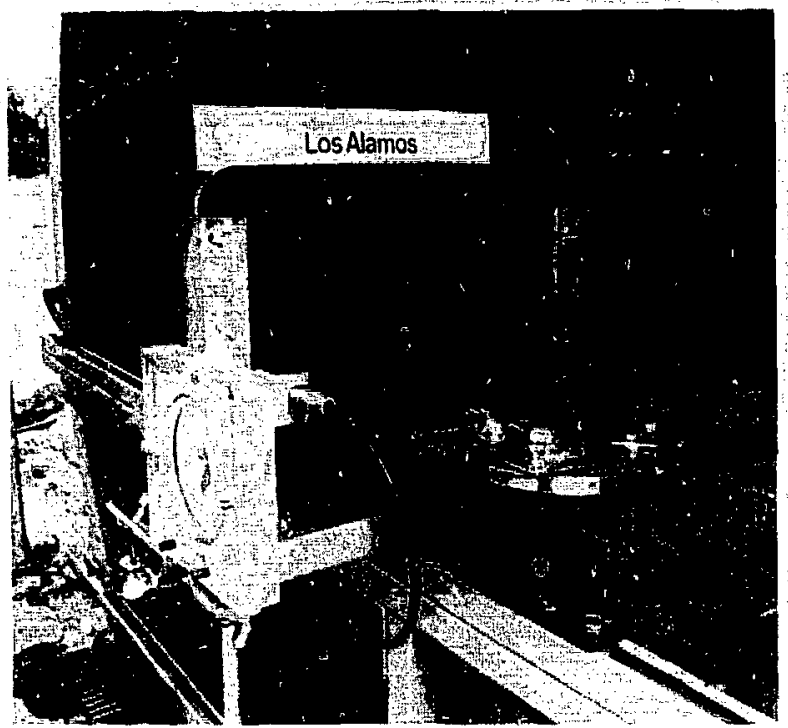

Fig. 16. Closeup view of the LWRHU target area for the fragment test.

were recovered nor was uranium detected in the posttest rjebris. Figures $17 a$ and $b, 18 a$ and $b$, and $19 a$ and b show profile views of fragment-impacted capsules and their longitudinal sections. None of these results indicate incipient fuel containment failure.

Based on the results from five of the seven fragment tests conducted, we conclude that the LWRHU assemblies mounted on a magnetometer ring can survive impact by an $18 \mathrm{-g}, .50$-caliber aluminum bullet at velocities greater than $750 \mathrm{~m} / \mathrm{s}(2460 \mathrm{ft} / \mathrm{s})$ but not as great as $900 \mathrm{~m} / \mathrm{s}(2950 \mathrm{ft} / \mathrm{s})$.

\section{Solid Rocket Propellant Fire}

A LWRHU assembly was exposed to a 10.5 -min fire of burning UPT-3001 solid rocket propellant to evaluate the ability of the heat source unit to withstand this environment in the event of a launch pad accident. For this test a $0.9 \times 0.9 \times 0.9 \mathrm{~m}(3 \times 3 \times 3 \mathrm{ft})$ cube of propellant weighing $1588 \mathrm{~kg}(3500 \mathrm{lb})$ was inhibited on five sides and placed on a sand bed with the uninhibited face vertical. Figure 20 shows a view of a cube of propellant with all but one of the cube faces inhibited. Simulant-fueled unit LRF 017 was placed. on the sand bed about $5 \mathrm{~mm}$ ( 2 in.) from the uninhibited propellant-cube face and with the cylindrical axis of the heat source horizontal and parallel to the cube face. After electrical ignition, the propellant burns with great intensity, and a violent flame zone approximately $4.6 \mathrm{~m}$. 
TABLE I. Bullet/Fragment Tests

\begin{tabular}{cccl} 
& \multicolumn{2}{c}{ Bullet Velocities } & \\
\cline { 2 - 3 } Unit ID & $(\mathrm{m} / \mathrm{s})$ & $(\mathbf{f t} / \mathbf{s})$ & \\
\hline & & & \multicolumn{1}{c}{ Results } \\
\hline 009 & 289 & 948 & Capsule deformed/not breached \\
005 & 661 & 2170 & Capsule deformed/not breached \\
008 & 773 & 2535 & Capsule not hit \\
018 & 775 & 2542 & Nothing recovered \\
169 & 757 & 2483 & Capsule deformed/not breached \\
003 & 940 & 3083 & Fragmented, U by chemistry \\
013 & 908 & 2979 & Fragmented, U by chemistry \\
\hline \hline
\end{tabular}

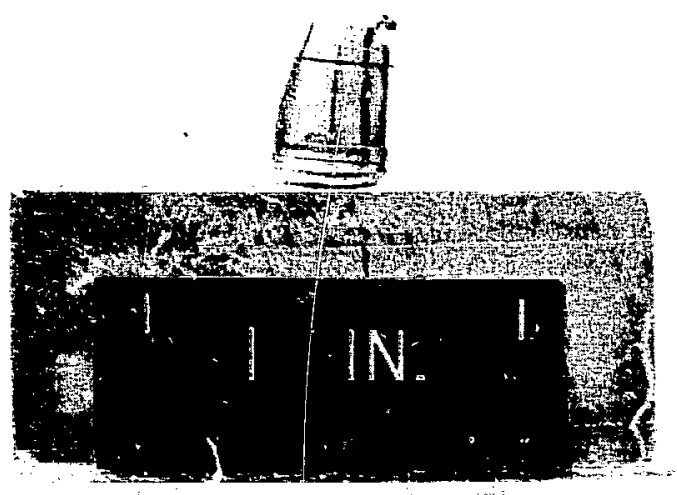

(a)

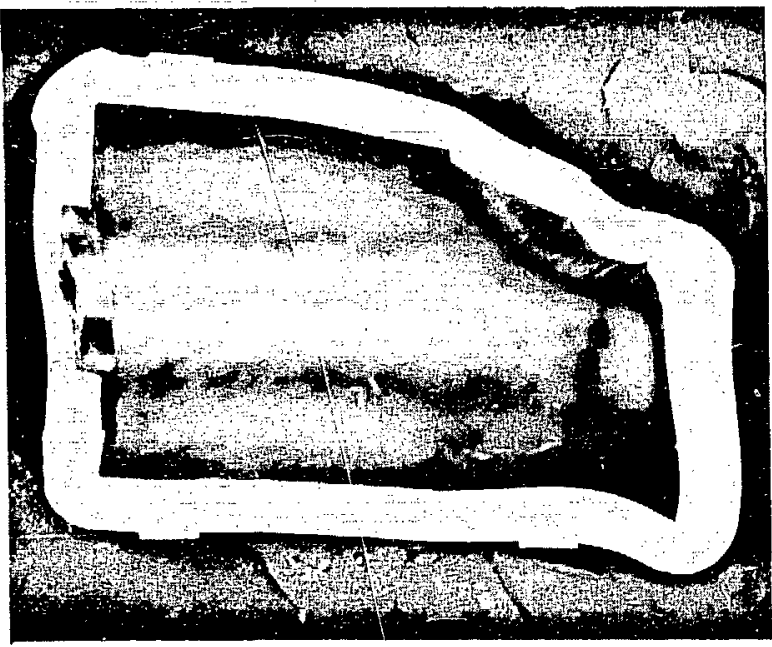

(b)

Fig. 17. Profile view of unit LRF 009 (a) after bullet impact at $289 \mathrm{~m} / \mathrm{s}$. (b) Longitudinal section of unit (8X).

(15 $\mathrm{ft})$ long emanates from the vertical cube face. Thermocouples placed in this zone measure temperatures of $\sim 2060^{\circ} \mathrm{C}$ out to distances of at least $1.8 \mathrm{~m}(6 \mathrm{ft})$. The $0.9-\mathrm{m}(3-\mathrm{ft})$ cube of solid rocket propellant burns for $10.5 \mathrm{~min}$. An overall view of the propellant-fire test is shown in Fig. 21.

After the fire test, the aeroshell of the test unit was intact. The surface that faced the fire was somewhat eroded and encrusted with propellant fire products, as can be seen in Fig. 22a. The aeroshell surface in contact with the sand bed was partially covered with a layer of fused sand. No $\alpha$-activity was detected on the exterior of the unit after the fire exposure. When the unit was disassembled, the outer and middle pyrolytic, graphite insulator bodies were found to be unchanged.
However, the inner insulator body, shown in Fig. 22b, had reacted with the Pt-Rh fuel capsule, presumably forming a Pt/Rh-C eutectic. The temperatures reported for the Pt-C and $\mathrm{Rh}-\mathrm{C}$ eutectics are $1705^{\circ} \mathrm{C}$ and $1694^{\circ} \mathrm{C}$. A longitudinal section of the fuel capsule (Fig. 22c) indicates the degree of interaction. As can be seen, the Pt vent frit has disappeared and the capsule wall thickness has been reduced in places to $0.41 \mathrm{~mm}$ $(0.016$ in.), which is $40 \%$ of its original thickness. There is, in addition, some evidence of a reaction between the $\mathrm{UO}_{2}$ fuel simulant and the inner surface of the fuel capsule. Obviously, the integrity of the unit has been greatly reduced by exposure to the $10.5-\mathrm{min}$. propellant fire. Yet the outer graphite components of the unit provided sufficient containment capability so 


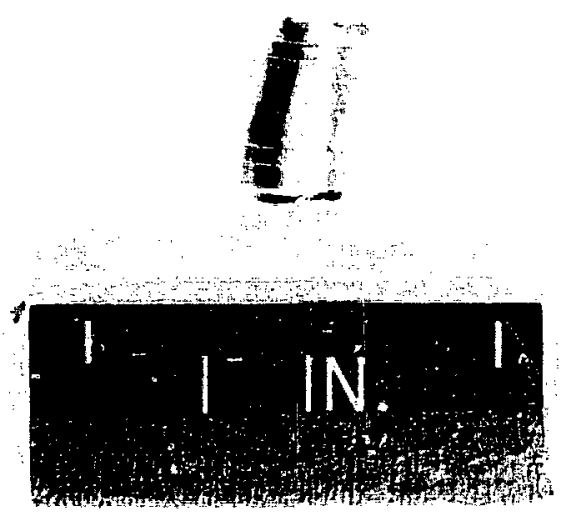

(a)

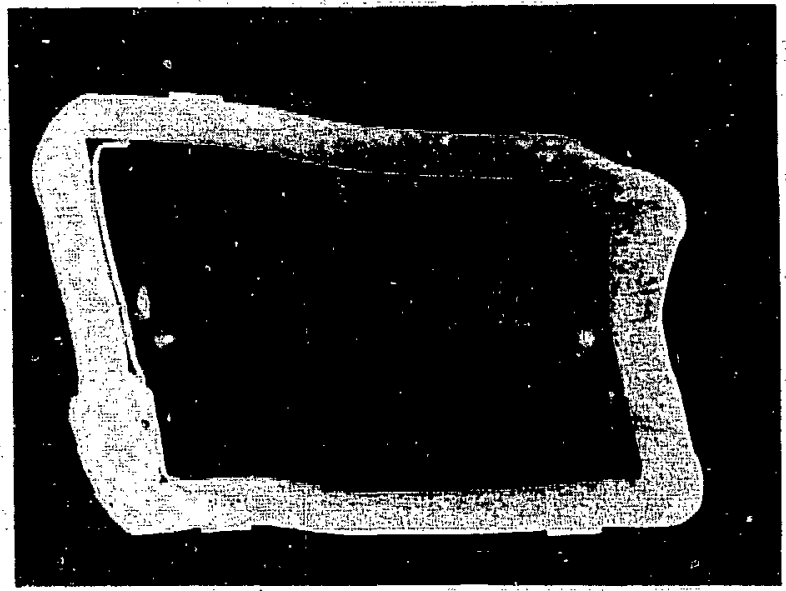

(b)

Fig. 18. Profile view of unit LRF 005 (a) afte bullet impact at $661 \mathrm{~m} / \mathrm{s}$. (b) Longitudinal section of unit ( $8 \mathrm{X}$ ).

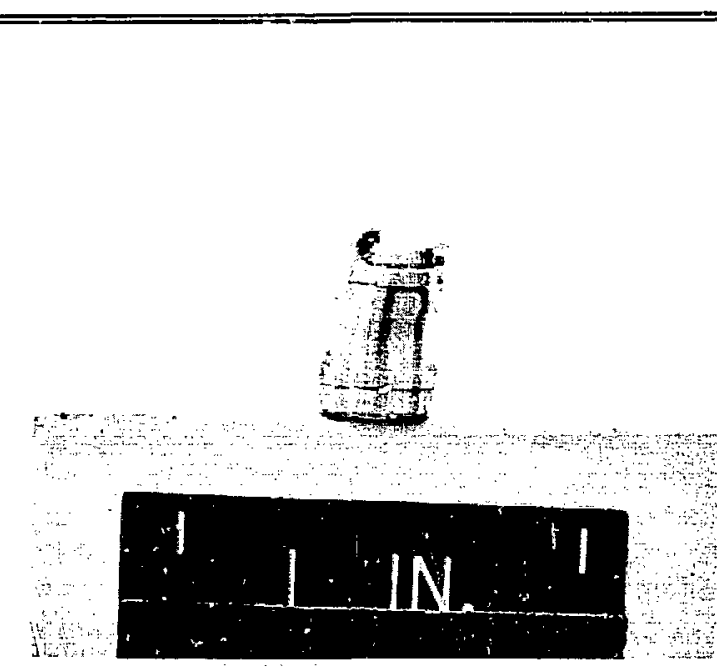

(a)

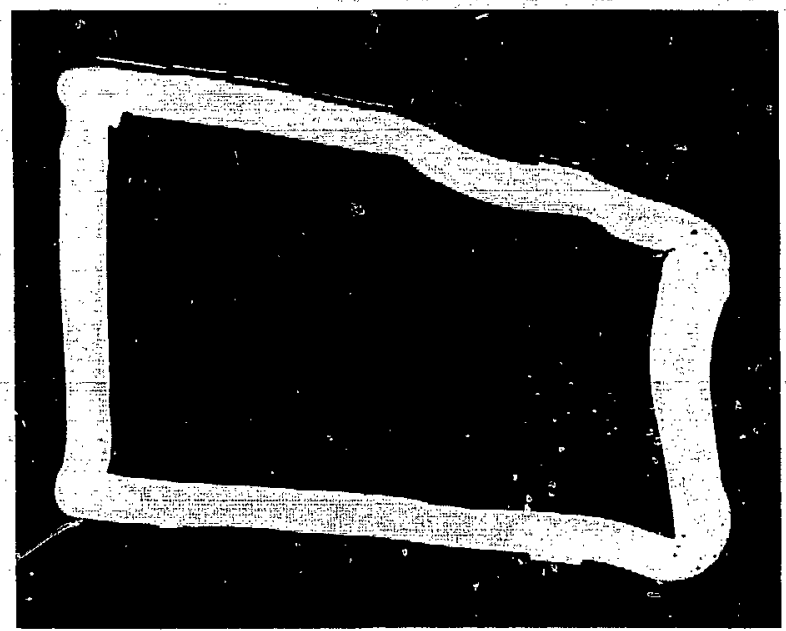

(b)

Fig. 19. Profile view of unit LRF 169 (a) after bullet impact at $757 \mathrm{~m} / \mathrm{s}$. (b) Longitudinal section of unit (8X).

that gross fuel dispersal would not occur if the unit were handled with reasonable care after a fire exposure.

\section{REENTRY ENVIRONMENTS}

LWRHU assembiles with production-grade ${ }^{238} \mathrm{PuO}_{2}$ fuel pellets were used in two types of reentry-accident environmental tests. Over the past decade, Los Alamos has developed equipment arid technology to impact fuel and its containment at high velocites in a manner that provides safe secondary containment of the ${ }^{238} \mathrm{Pu}$ fuel. Similarly, aquariums and autoclaves have been developed to expose ${ }^{238} \mathrm{Pu}$ fuel to sea level and deep-ocean environments and at the same time provide satisfactory containment of the fuel within the environmental chambers. 


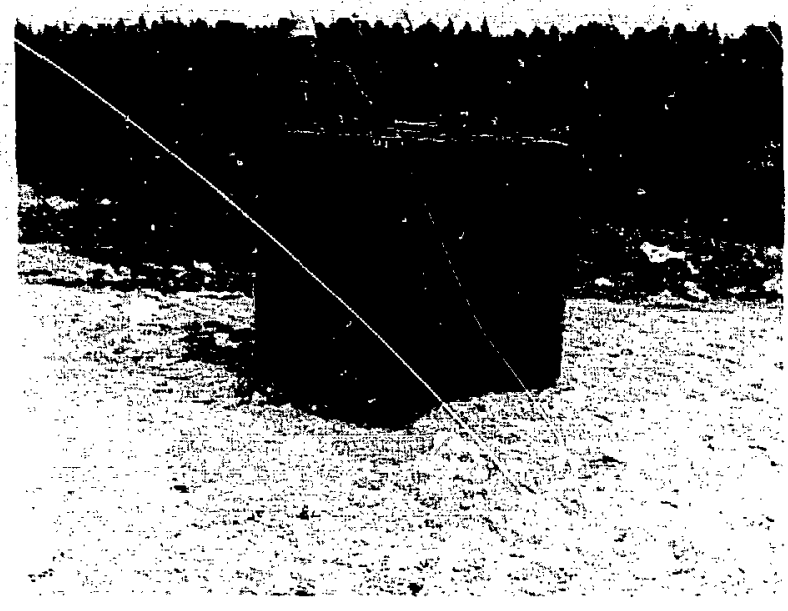

Fig. 20. Solid rocket propellant cube.

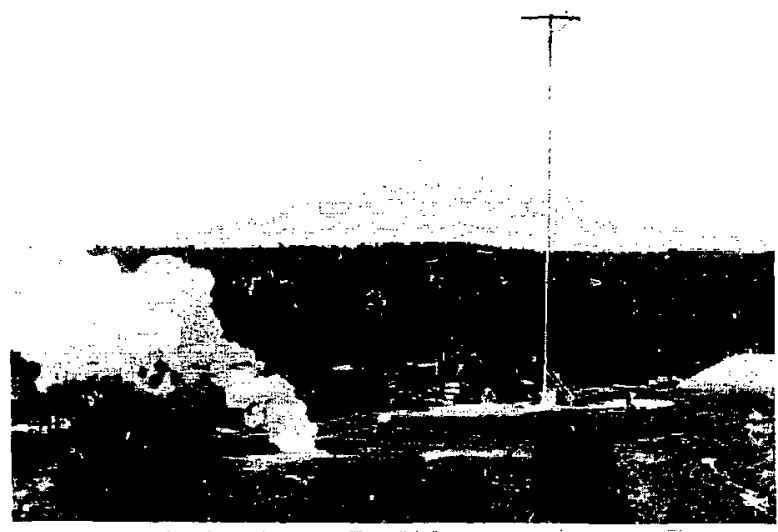

Fig. 21. View of the solid rocket propellant fire.

\section{A. Impact}

Six LWRHU assemblies with ${ }^{238} \mathrm{PuO}_{2}$ fuel pellets were impacted in the Los Alamos Isotope Fuels impact Tester (IFIT), a 178-mm (7-in.) bore gas gun designed specifically for the impact testing of fueled radioisotope heat sources. ${ }^{3}$ In this gun, the heat source is instrumented with thermocouples and set on an orientation cradle resting on an inner projectile cylinder, which rests, in turn, on an outer projectile cylinder that rides in the smooth bore of the gun barrel. Com- pressed gas drives this projectile assembly vertically to the end of the $3.65-\mathrm{m}(12-\mathrm{ft})$ barrel, where the outer and inner projectile cylinders are stopped by and seal the tapered throats of the outer and inner catch tubes, respectively. The sample continues to fly to the end of the inner catch tube, where it impacts the target placed there.

Four units, LRF 021 through 024, were impacted "as built" shortly after their assembly. Two units, LRF 011 and 020 , were stored at ambient tempereture $\left(\sim 45^{\circ} \mathrm{C}\right)$ for about $2.5 \mathrm{yr}$ and then impacted. The nominal impact velocity for all tests was $49 \mathrm{~m} / \mathrm{s}(161 \mathrm{ft} / \mathrm{s})$, which is $110 \%$ of the predicted reentry impact velocity at sea level, and the nominal temperature of the units just before impact was in the range of 25 to $50^{\circ} \mathrm{C}$. The units were impacted in various orientations with respect to the vent end of the capsule. By convention, the angle is specified as the angle the flight trajectory makes with the cylindrical axis of the heat source; that is, the angle for a unit impacted on the vent end is $0^{\circ}$, on the side is $90^{\circ}$, and on the closure end is $180^{\circ}$. Before the actual impact test, each fueled capsule was removed from its graphite components and heated in an electron-beam furnace through a short duration thermal pulse to simulate the heating in a reentry event. In Figs. 23a through $f$, the thermal records of the treatment each unit received are shown and compared with the thermal pulse predicted by computes calculation at the Applied Physics Laboratory. The reentry impact conditions and results are summarized in Table II.

Figures 24 and 25 are coinposite photographs of the six units after impact. The graphite components are sigrificantly damaged, as rnight be expected. As can seen, there is little or no damage or distortion to the fuel capsules because the graphite provides considerable protection. A small crack was observed in the interior of the ciosure weld zone of LRF 011, aged 2.5 yr before impact, but the unit was not breached. No conclusion has been reached as to the cause of this small crack. During the engineering development of the LWRHU, ${ }^{1}$ capsules were impacted without graphite at $48 \mathrm{~m} / \mathrm{s}(157 \mathrm{ft} / \mathrm{s})$ in the $0^{\circ}, 45^{\circ}$, and $90^{\circ}$ orientations. They were also impacted in the $90^{\circ}$ orientation at successively higher velocites $(68,88,105$, and $128 \mathrm{~m} / \mathrm{s}$ ) 'vith substantial deformation but without failure. The development tests on the bare capsules and the safety analysis tests on capsules with graphite protection demonstrate that the ductile Pt-30 Rh alloy capsule provides excellent fuel containment capability under postulated impact conditions.

The condition of the fuel after impact, especially the amount of respirable particles, is of considerable interest. Accordingly, the size distribution of the fuel in each of the six impacted LWRHUs was determined. The capsules were defueled under distilled water with care to collect all the ${ }^{238} \mathrm{PuO}_{2}$ fragments and particles. The 


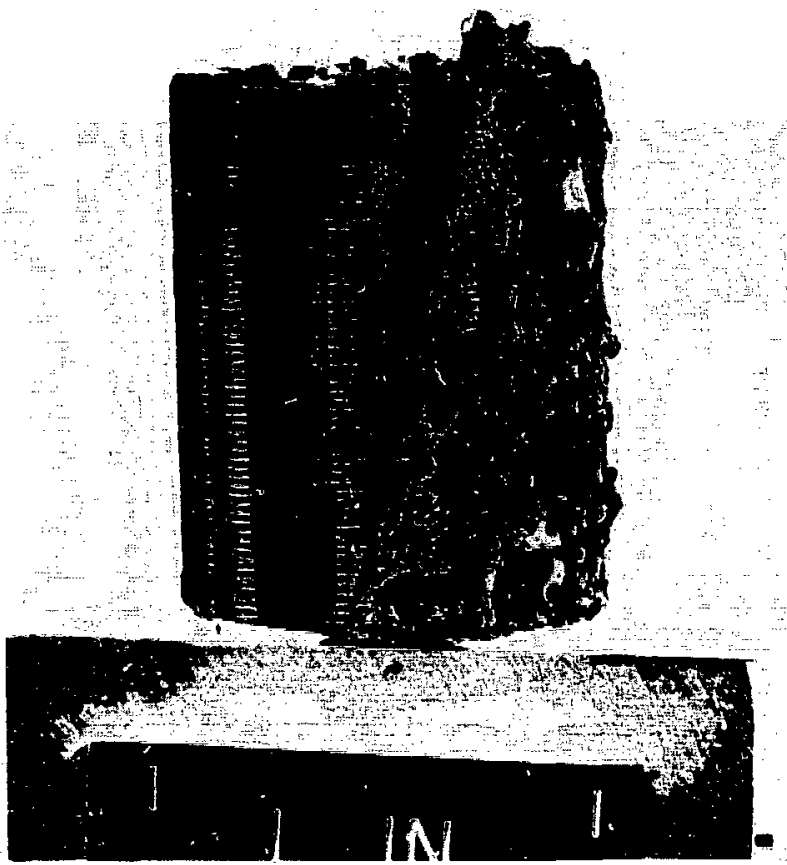

(a)

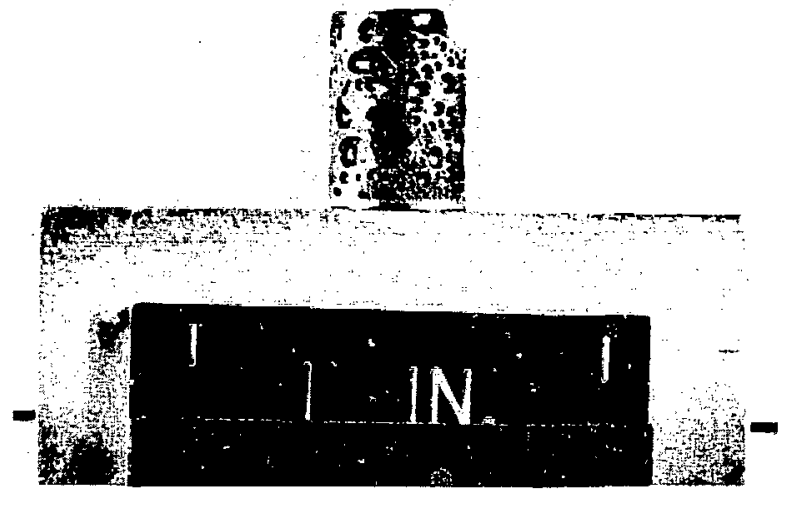

(b)

fuel and its entraining liquid were sieved through a series of screens. All operations were conducted with the sieve and its contents submerged in a beaker of clean distilled water. The beaker with its contents was placed in an ultrasonic cleaner and agitated manually. When no more material passed through the sieve, the material remaining on the sieve was washed into a tared weighing bottle, dried, cooled, and weighed. The procedure was repeated for each sieve size. The material passing through the $<10-\mu \mathrm{m}$ sieve was coliected,

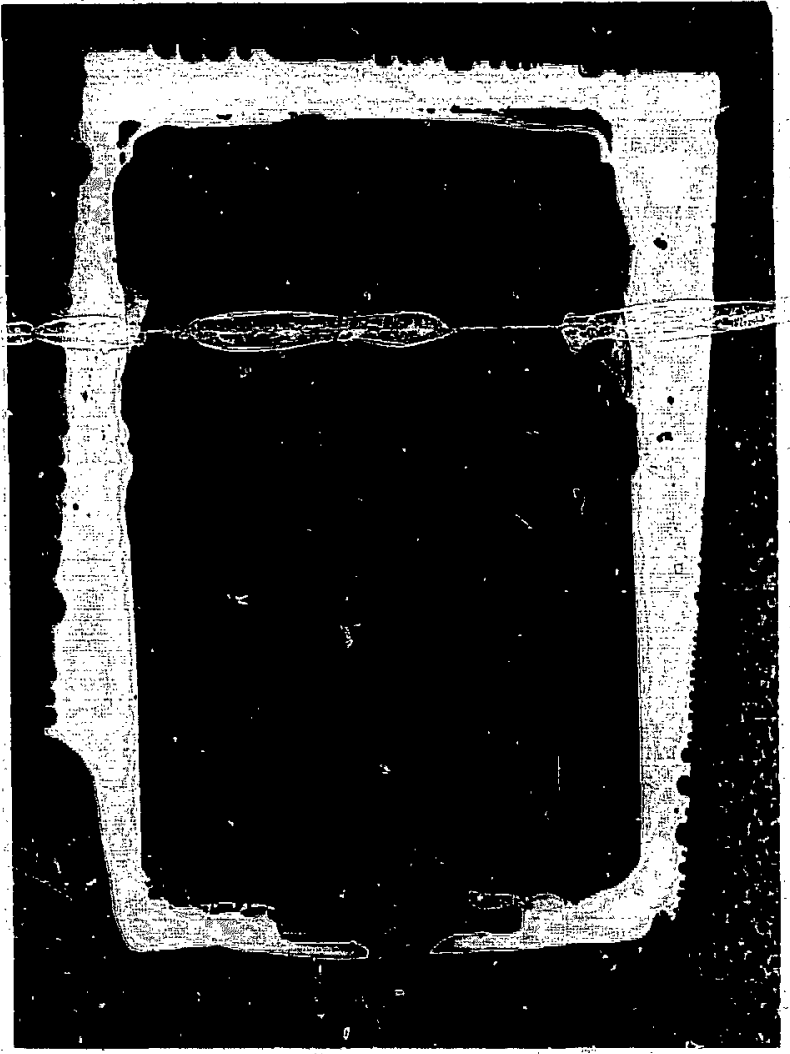

(c)

Fig. 22. Unit LRF 017 (a) after propellant fire and (b) with inner graphite insulator showing reaction with the capsule; (c) longitudinal section of the fuel capsule (8X).

dried, and weighed. After being weighed, the $<10-\mu \mathrm{m}$ fraction was resuspended in distilled water and agitated ultrasonically. A small portion of this suspension was placed on a glass microscope slide and allowed to dry. The dried particles were removed from the slide with replicating tape and prepared for examination by electron microscopy. The size distribution was determined by counting at least 2000 particles. The size distributions are presented in Table III.

Of most interest is the fraction $<4 \mu \mathrm{m}$, the fraction considered to be respirable and therefore most hazardous if dispersed in the atmosphere. The impacted fuel from the two aged units contained 3-4 times more respirable fines than the fuel from the as-built units, probably because the helium stored during the aging period was released to the grain boundaries during the reentry heating, which resulted in the aged fuel being weaker. 


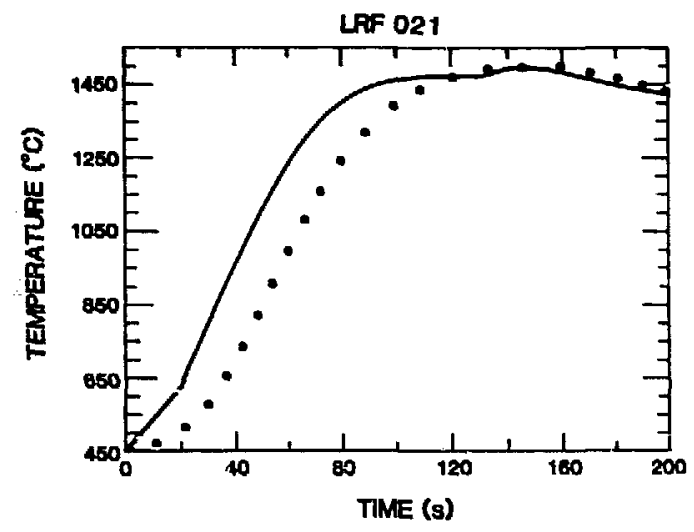

(a)

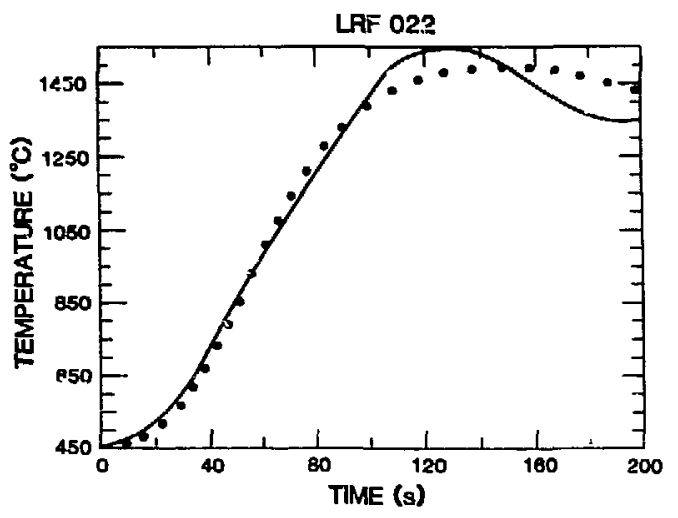

(b)

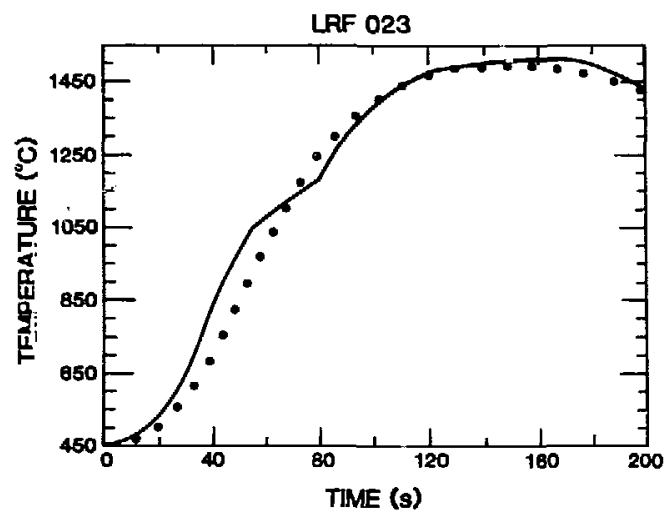

(c)

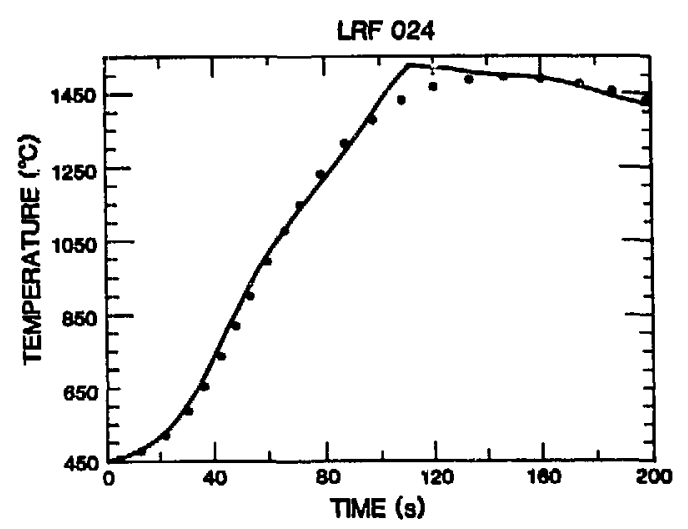

(d)

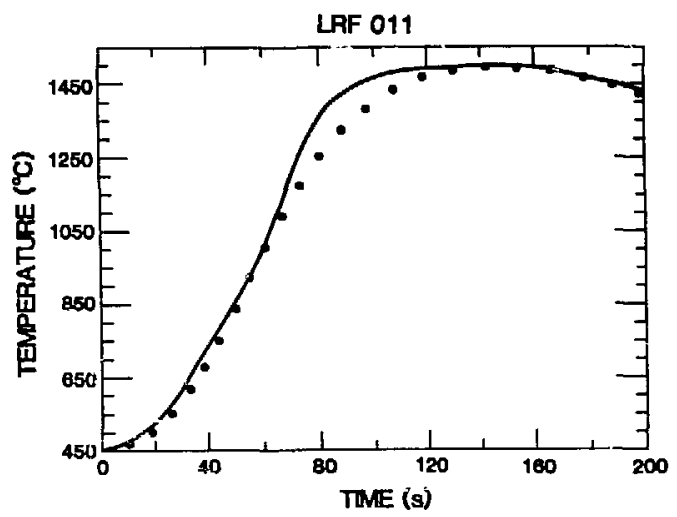

(e)

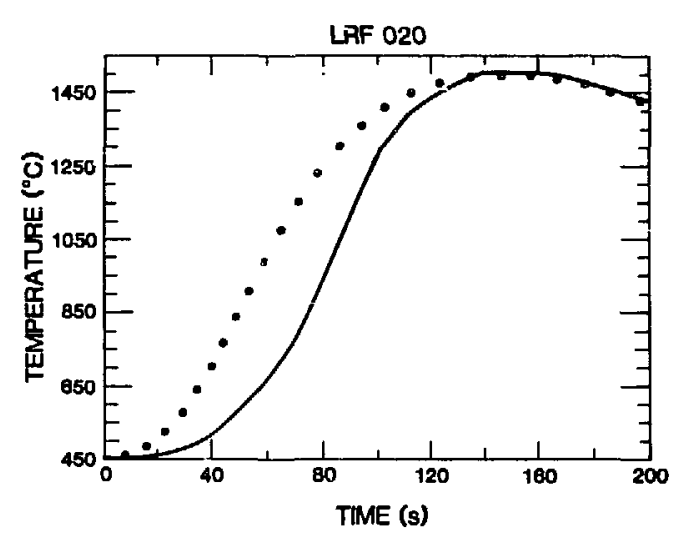

(f)

Fig. 23. The the mal histories of six LWRHU capsules compared with computer-predicted level of reentry heating. (a) LRF 021 , (b) LFR 022, (c) LRF 023, (d) LRF (24. (e) LRF 011, and (f) LRF 020. 
TABLE II. Reentry Impact Tests

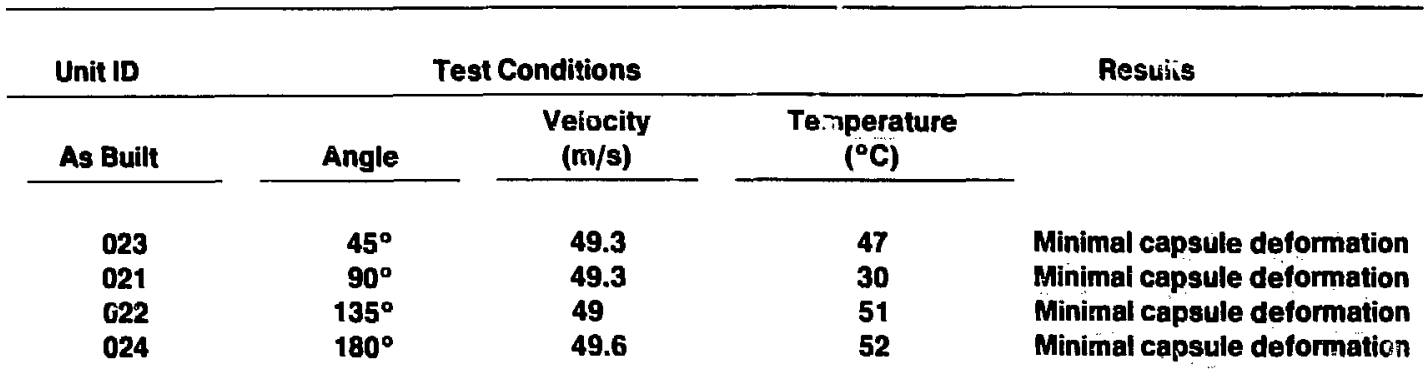

Aged 2.5 yr

\begin{tabular}{|c|c|c|c|c|}
\hline $\begin{array}{l}011 \\
020\end{array}$ & $\begin{array}{r}135^{\circ} \\
90^{\circ}\end{array}$ & $\begin{array}{l}49.9 \\
49.2\end{array}$ & $\begin{array}{l}24 \\
26\end{array}$ & $\begin{array}{l}\text { Cracked weid/not breached } \\
\text { Minimal capsule deformation }\end{array}$ \\
\hline
\end{tabular}
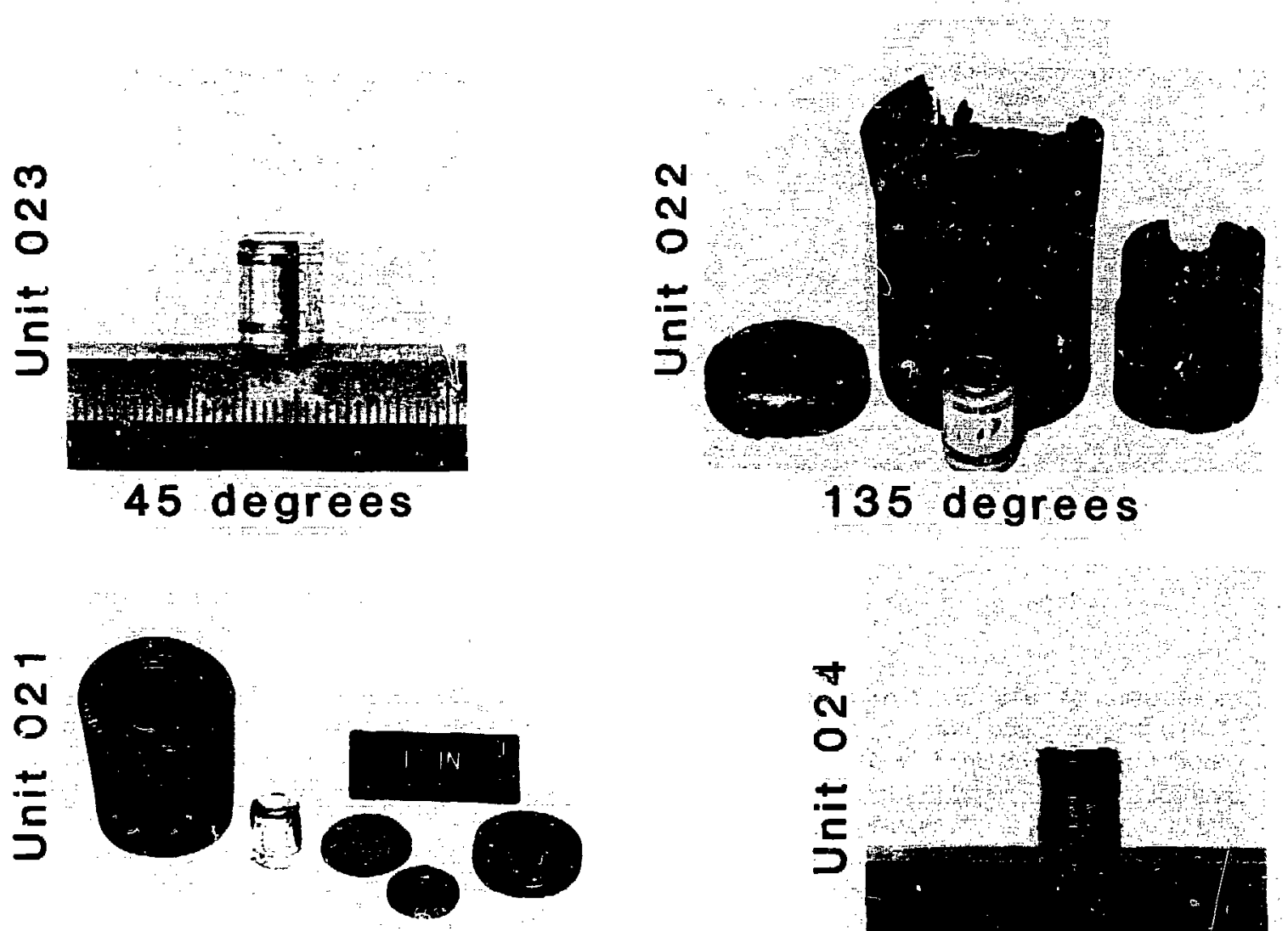

90 degrees

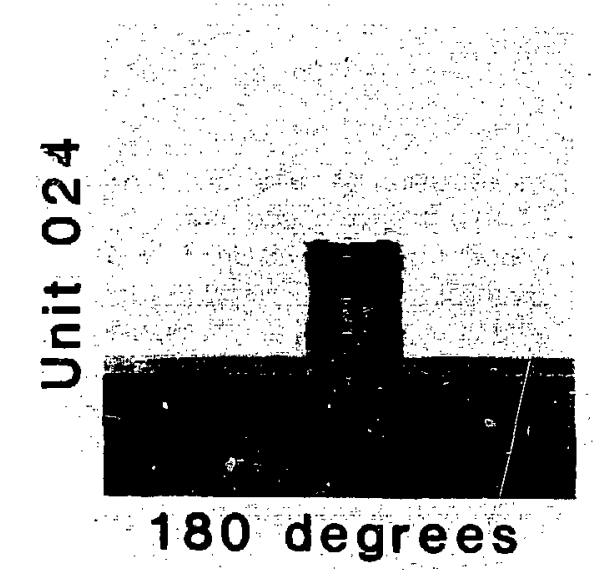

Fig. 24. As-built units after impact at $49 \mathrm{~m} / \mathrm{s}$. 


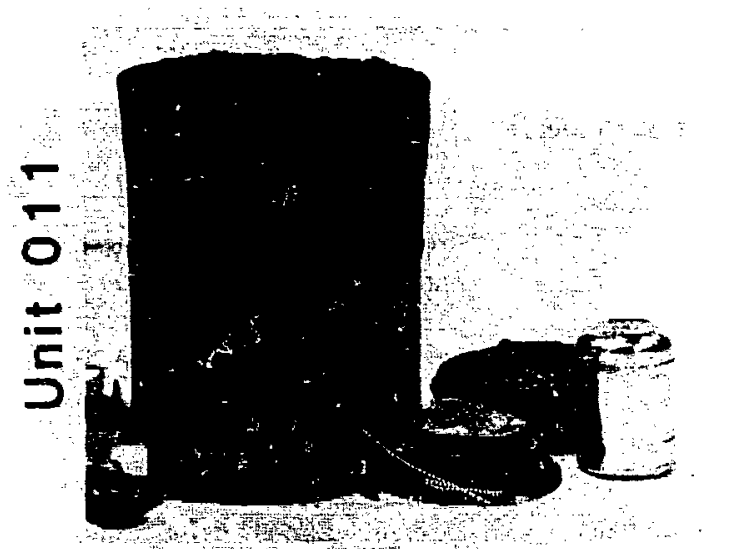

135 degrees

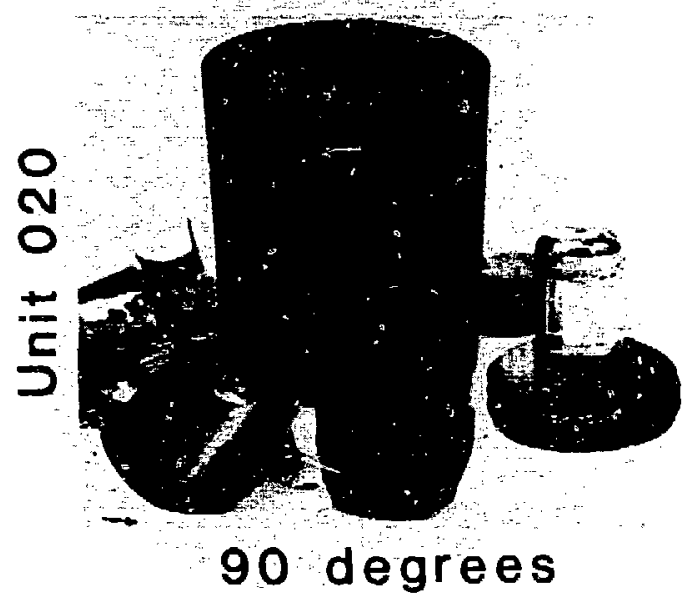

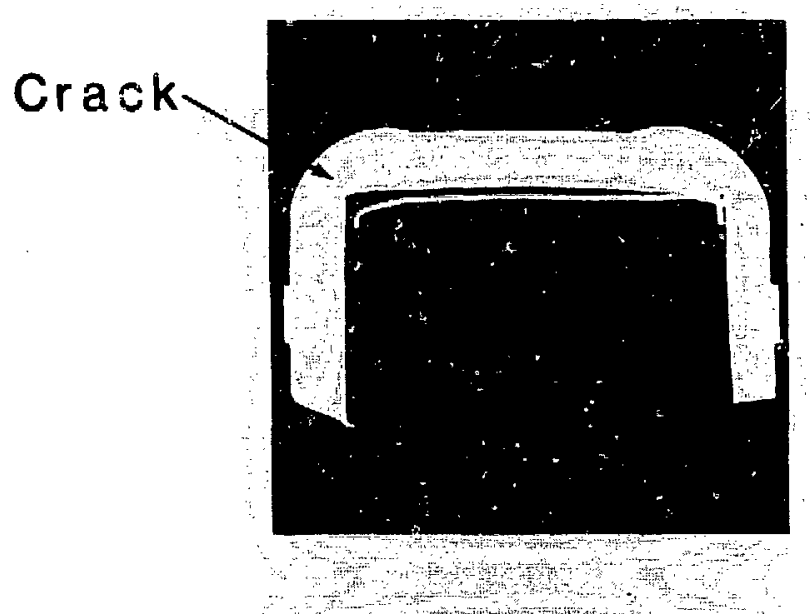

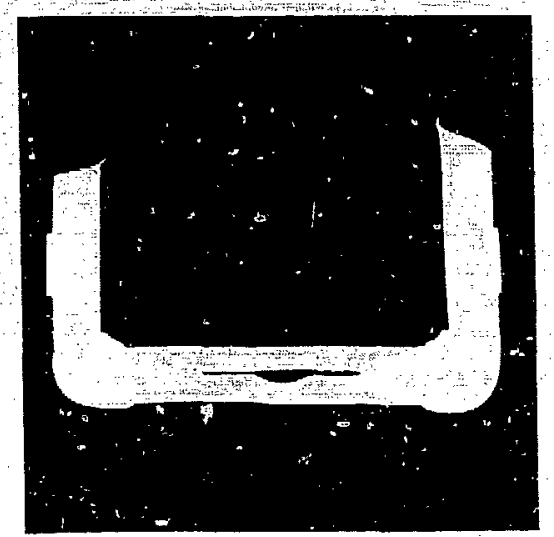

Fig. 25. Units aged $2.5 \mathrm{yr}$ and then impacted at $49 \mathrm{~m} / \mathrm{s}$.

\section{B. Seawater immersion}

Two LWRHU assemblies with open vents were exposed to seawater at $10^{\circ} \mathrm{C}$ for approximately $1.75 \mathrm{yr}$. Unit LRF 019 was exposed in an aquarium at $0.25-\mathrm{m}$ (10-in.) depth for 640 days. Unit LRF 010 was exposed in the Hydrostatic Test Facility (a Monel autoclave) at Los Alamos for 639 days at a pressure of 68.9 MPs (10 $000 \mathrm{psi}$ ), the equivalent of $6000-\mathrm{m}$ ocean depth. The concentration of plutonium in the seawater in both chambers was measured weekly.

After the exposures to the seawater, the LWRHUs were recovered and their graphite components were ashed, and the amount of plutonium in each residue was measured. We recovered $32 \mu \mathrm{g}$ from LRF 019 (shallow depth), and $154 \mu \mathrm{g}$ was recovered from LRF 010 (deep-ocean environment). Possibly, release of the hydrostatic pressure tends to pump very fine particles of fuel through the vent frit and deposit them in the graphite, which acts as a filter medium. Therefore, this release phenomenon would not occur until the pressure was released, and the quantity may depend on the pressure release rate. Results of the weekly sampling of the aquatic media for plutonium concentration are presented in Table IV. Neither exposure showed evidence of reaction between the seaw/ater and the Pt-30 Rh fuel capsules or between the seawater and the ${ }^{238} \mathrm{PuO}_{2}$ fuel. 


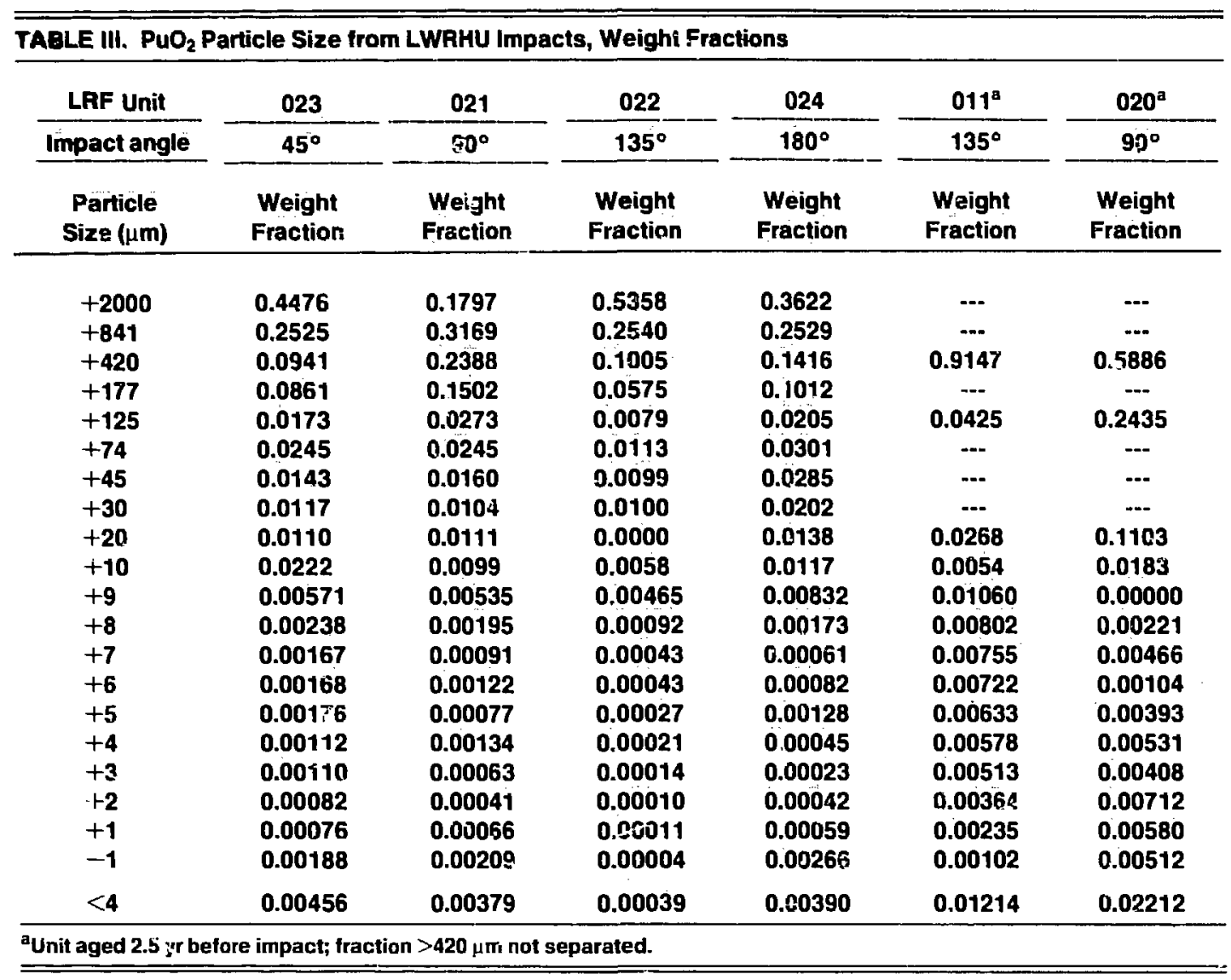

\section{v. CONCLUSIONS}

A series of safety tests has been performed on the Light Weight Radioisotope Heater Unit (LWRHU). These tests were conducted over a 3-yr period using a shock tube at Sandia National Laboratories' Coyote Test Range (Albuquerque, New Mexico), and using, at Los Alamos, a .50-caliber gun at Q-Site, an explosive burn area at $\mathrm{K}$-Site, the Isotope Fuels Impact Tester at 10-Site, and both ambient and high-pressure aquariums in the CMR building. The tests simulate the thermal and mechanical environments postulated for spacecraft accidents on the launch pad and on reentry abort. The tests demonstrate almost complete containment of the fuel, or fuel simulant (depleted $\mathrm{UO}_{2}$ ), in the following:

(1) an overpressure environment of $12.76 \mathrm{MFa}$ (1850 psi),

(2) on impact by an 18-g aluminum fuel-tank fragment at velocities greater than $750 \mathrm{~m} / \mathrm{s}(2450$ $\mathrm{ft} / \mathrm{s})$ but less than $900 \mathrm{~m} / \mathrm{s}(2950 \mathrm{ft} / \mathrm{s})$,

(3) during a 10.5-min burn of a $0.9 \times 0.9 \times 0.9 \mathrm{~m}(3 \times$ $3 \times 3 \mathrm{ft}$ ) block of solid rocket motor propellent,
(4) after impact at $49 \mathrm{~m} / \mathrm{s}(161 \mathrm{ft} / \mathrm{s})$ in four different orientations on a hard surface, and

(5) during immersion in seawater for $1.75 \mathrm{yr}$ at both sea level pressure and at a pressure equivalent to $6000 \mathrm{~m}(19700 \mathrm{ft})$ ocean depth.

\section{ACKNOWLEDGMENTS}

The environmental safety analysis testing of the LWRHU was done at a number of facilities at Los Alamos and at Sandia National Laboratories' Coyote Test Range in Albuquerque. C. M. Seabourn developed the test plan and supervised the early tests in the series. F. H. Matthews supervised the overpressure testing at Coyote Test Range and interpreted data from the shock-tube tests. The fragment testing was done under the direction of $M$. A. Fletcher, the propellent burn under the direction of $E$. E. Abeyta, the impact testing under the direction of C. E. Frantz, and the seawater-immersion tests under the direction of $\mathrm{J}$. H. Patterson. D. S. Garinger performed the particlesize analysis on the ${ }^{238} \mathrm{PuO}_{2}$ fuel after the tests. M. A. 


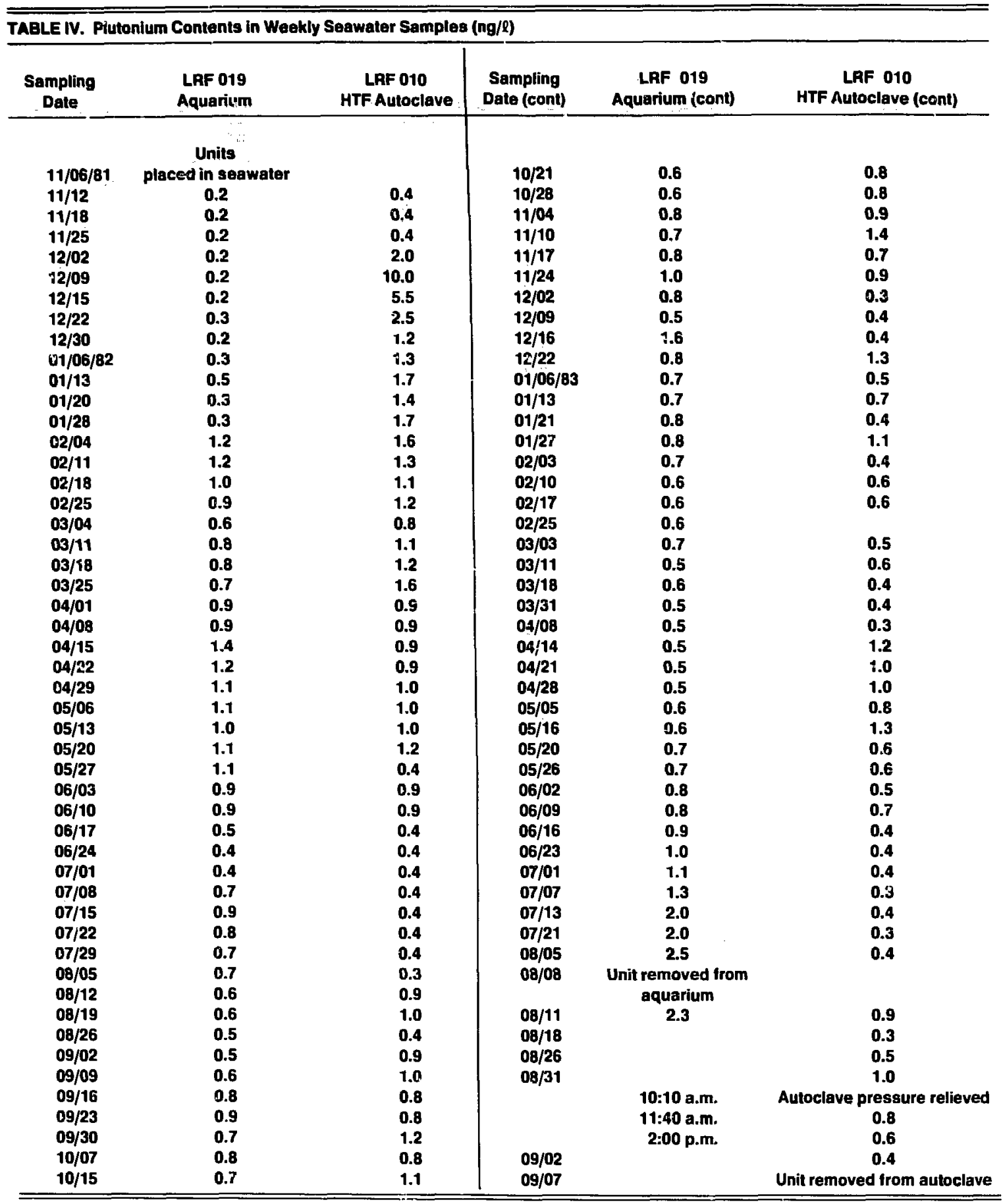


Casey and J. I. Archuleta contributed to the metaliographic postmortem examination of the units tested.

\section{REFERENCES}

1. R. E. Tate, "The Light Woight Radioisotope Heater Unit (LWRHU): A Technical Description of the Reference Design," Los Alamos National Laboratory report LA-9078-MS (January 1982).
2. C. M. Seabourn, "Light Weight Radioisotope Heater Unit Safety Test Plan," Los Alamos National Laboratory memorandum CMB-5-C-81-11 (May 1981).

3. C. E. Frantz, J. W. Taylor, and D. B. Court, "Isotope Fueis Impact Tester (IFIT)," Los Alamos Scientific Laboratory report LA-6013 (Januar :976). 